Article

\title{
Zingiber officinale Roscoe Rhizomes Attenuate Oxaliplatin-Induced Neuropathic Pain in Mice
}

\author{
Ji Hwan Lee ${ }^{1,2}$, Daeun Min ${ }^{1,2}$, Donghun Lee ${ }^{3 \oplus}$ and Woojin Kim ${ }^{1,2, *(\mathbb{C})}$ \\ 1 Department of Physiology, College of Korean Medicine, Kyung Hee University, Seoul 02453, Korea; \\ mibdna@khu.ac.kr (J.H.L.); wndqhr1456@gmail.com (D.M.) \\ 2 Department of Science in Korean Medicine, Graduate School, Kyung Hee University, Seoul 02453, Korea \\ 3 Department of Herbal Pharmacology, College of Korean Medicine, Gachon University, \\ Gyeonggi-do 13120, Korea; dlee@gachon.ac.kr \\ * Correspondence: wjkim@khu.ac.kr; Tel.: +82-2-961-0334
}

Citation: Lee, J.H.; Min, D.; Lee, D.; Kim, W. Zingiber officinale Roscoe

Rhizomes Attenuate

Oxaliplatin-Induced Neuropathic Pain in Mice. Molecules 2021, 26, 548. https://doi.org/10.3390/molecules 26030548

Academic Editors:

Krzysztof Kamiński and Rafal

M. Kaminski

Received: 22 December 2020

Accepted: 20 January 2021

Published: 21 January 2021

Publisher's Note: MDPI stays neutral with regard to jurisdictional claims in published maps and institutional affiliations.

Copyright: (c) 2021 by the authors. Licensee MDPI, Basel, Switzerland. This article is an open access article distributed under the terms and conditions of the Creative Commons Attribution (CC BY) license (https:// creativecommons.org/licenses/by/ $4.0 /)$.

\begin{abstract}
Oxaliplatin is a platinum derivative chemotherapeutic drug widely used against cancers, but even a single treatment can induce a severe allodynia that requires treatment interruption and dose diminution. The rhizome of Zingiber officinale roscoe (Z. officinale, ginger), has been widely used in traditional medicine to treat various diseases causing pain; however, its effect against oxaliplatininduced neuropathic pain has never been assessed. In mice, a single oxaliplatin $(6 \mathrm{mg} / \mathrm{kg}$, i.p.) treatment induced significant cold and mechanical allodynia. Cold and mechanical allodynia were assessed by acetone drop and von Frey filament tests, respectively. Water extracts of Z. officinale (100, 300 , and $500 \mathrm{mg} / \mathrm{kg}$, p.o.) significantly attenuated both cold and mechanical allodynia induced by oxaliplatin. Intrathecal pre-treatment with the antagonist 5-HT $1 \mathrm{~A}$ (NAN-190, i.t., $1 \mu \mathrm{g}$ ), but not with the antagonist 5- $\mathrm{HT}_{2 \mathrm{~A}}$ (ketanserin, i.t., $1 \mu \mathrm{g}$ ), significantly blocked the analgesic effect of $Z$. officinale against both cold and mechanical allodynia. However, 5-HT 3 antagonist (MDL-72222, i.t., $15 \mu \mathrm{g}$ ) administration only blocked the anti-allodynic effect of $Z$. officinale against cold allodynia. Real-time PCR analysis demonstrated that $Z$. officinale significantly increased the mRNA expression of the spinal $5-\mathrm{HT}_{1 \mathrm{~A}}$ receptor that was downregulated after oxaliplatin injection. These results suggest that Z. officinale may be a viable treatment option for oxaliplatin-induced neuropathic pain.
\end{abstract}

Keywords: allodynia; chemotherapy-induced neuropathic pain; oxaliplatin; serotonin; Zingiber officinale

\section{Introduction}

Oxaliplatin is a widely used chemotherapeutic agent and was the first diaminocyclohexane platinum-based anti-cancer agent to be approved for the treatment of colorectal cancer [1]. Moreover, it has a better safety profile than cisplatin or carboplatin, which are other platinum-based drugs, as it bears no hepatoxicity or nephrotoxicity [2]. However, the use of oxaliplatin in cancer patients is limited due to the severe acute neuropathic pain induced even after a single injection in up to $80 \%$ of treated patients [3]. These paresthesia and dysesthesia can initiate acutely within $48 \mathrm{~h}$ after its administration [4] and are known to peak three days after its administration [5]. For the past several years, our lab has focused its efforts on understanding the mechanism of action of oxaliplatin-induced neuropathic pain [6,7] and on finding an effective treatment that bears no side effects [8-10]. However, an optimal drug has yet to be found, and the development of alternative strategies is continuously needed.

Zingiber officinale roscoe (Z. officinale) is a member of the Zingiberaceae family and is commonly known as ginger. For thousands of years, Z. officinale has been used worldwide, especially in East Asia to attenuate cold, headache, and digestive problems [11,12]. Chemical analysis show that Z. officinale contains more than 400 different compounds and, as major biologically active compounds, it includes gingerols, shogaols, and paradols [13]. In addition, amino acids, raw fiber, ash, protein, phytosterols, vitamins, and minerals are 
also reported to be present [14]. Experimental studies conducted in rodents reported that Z. officinale has various therapeutic effects such as anti-inflammatory [15], hypoglycemic [16], and anti-emetic [17] effects. Furthermore, in some animal models of pain, Z. officinale significantly attenuated muscle pain [18] and diabetes- and injury-induced neuropathic pain $[19,20]$, showing therapeutic potential in inhibiting chemotherapy-induced neuropathic pain. However, to date, its effect against oxaliplatin-induced neuropathic pain has never been assessed.

Serotonin (5-hydroxytryptamine; 5-HT) is a small-molecule neurotransmitter, which is known to be involved in the descending pain inhibitory system [21,22]. It is known to be synthesized in the rostro ventromedial medulla (RVM), and axons of serotonergic neurons are present in the descending pathway to the spinal cord. It is known that 5-HT is able to interact with 7 different classes of receptors that are differentiated into 15 subtypes [23]. Although most of these receptors are present in the spinal dorsal horn neurons, their involvement in pain modulation remains largely unknown, and studies conducted on pain have been mainly focused on $5-\mathrm{HT}_{1}, 5-\mathrm{HT}_{2}$, and $5-\mathrm{HT}_{3}$ receptors [24]. However, even the role of these receptors in pain attenuation remains to be elucidated, as their involvements appears inconsistent depending on the disease models and drugs used [25]. In oxaliplatin-induced neuropathic pain, spinal 5-HT receptors have also been reported to play an important role, as the analgesic actions of various treatments were blocked by pre-treatment with spinal 5-HT receptor antagonists [8,26,27]. Furthermore, the American Society of Clinical Oncology has recommended duloxetine, a serotonin and norepinephrine reuptake inhibitor, to be used against oxaliplatin-induced neuropathic pain [28]. However, although duloxetine is known to possess more selective re-uptake inhibition and binding of the 5-HT transporter with respect to the norepinephrine transporter [29], the role of 5-HTergic neurotransmission in oxaliplatin-induced neuropathic pain is still a controversial issue [30], and further investigation is needed.

Thus, the aim of this study was, first, to assess the analgesic effect of $Z$. officinale on oxaliplatin-induced neuropathic pain. Second, to assess the involvement of spinal 5-HT receptors in the anti-allodynic effect of Z. officinale. Finally, to analyze whether the messenger RNA (mRNA) expression level of spinal 5-HT receptors could be modified following oxaliplatin and Z. officinale treatments.

\section{Results}

\subsection{Oxaliplatin Administration Induces Cold and Mechanical Allodynia in Mice}

Following a single intraperitoneal injection of oxaliplatin $(6 \mathrm{mg} / \mathrm{kg})$, significant cold and mechanical allodynia were induced on day three (D3) and day five (D5) (Figure 1a,b). These results are in accordance with our previous study showing that a single oxaliplatin treatment induced cold and mechanical allodynia 3 to 7 days after injection [8]. On D3 and D5, cold allodynia was strongly induced in oxaliplatin-injected mice compared to mice treated with $5 \%$ glucose (control, $p<0.0001$ ), as shown in Figure 1a. In the von Frey test, the $50 \%$ threshold value also significantly lowered both on D3 $(p<0.01)$ and on D5 $(p<0.05)$ after oxaliplatin injection compared to control (Figure 1b). Cold allodynia was measured by using the acetone drop test, and mechanical allodynia was assessed by using the von Frey filament test.

\subsection{Anti-Allodynic Effect of Z. officinale on Oxaliplatin-Induced Neuropathic Pain in Mice}

To observe the analgesic effect of Z. officinale on oxaliplatin-induced cold and mechanical allodynia, three different doses of $Z$. officinale $(100,300$, or $500 \mathrm{mg} / \mathrm{kg}$ ) were administered orally at D3, when significant cold and mechanical allodynia were evident in mice. Behavioral tests were conducted before and $30 \mathrm{~min}, 60 \mathrm{~min}$, and $90 \mathrm{~min}$ after the injection of $Z$. officinale. The results showed significant alleviation of cold allodynia in a dose-dependent manner $60 \mathrm{~min}$ after Z. officinale treatment (Figure 2a). Z. officinale treatment also caused a significant increase of the $50 \%$ threshold value compared to control (distilled water; DW), which began $30 \mathrm{~min}$ after the injection and lasted for $60 \mathrm{~min}$ 
(Figure 2b). However, for both cold and mechanical allodynia, the analgesic effect of $Z$. officinale disappeared after $90 \mathrm{~min}$. In our following experiments, $300 \mathrm{mg} / \mathrm{kg}$ of $Z$. officinale was used. Furthermore, the same dose of Z. officinale ( $300 \mathrm{mg} / \mathrm{kg}$, p.o.) treatment in naïve mice induced no significant change in behavioral responses in the acetone drop and von Frey filament tests compared to DW-injected mice (Figure 2c,d).

(a) Acetone Drop Test

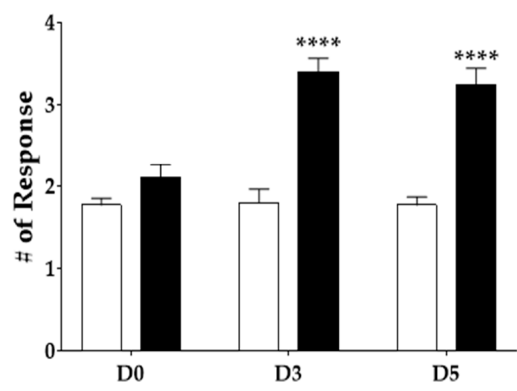

(b) Von Frey Test

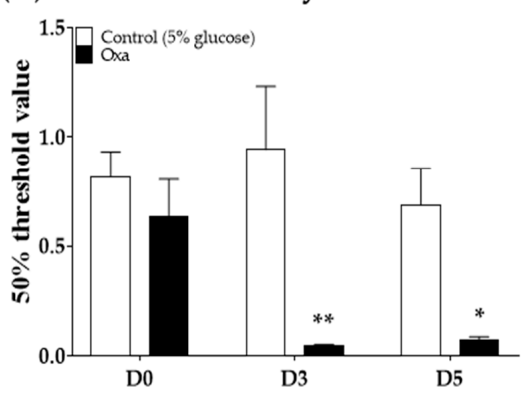

Figure 1. Induction of cold and mechanical allodynia by a single intraperitoneal injection of oxaliplatin in mice. Three to 5 days after a single injection of oxaliplatin $(6 \mathrm{mg} / \mathrm{kg}$, i.p.), cold (a) and mechanical (b) allodynia were produced. Cold and mechanical allodynia were assessed by using the acetone drop and von Frey filament tests, respectively. Control mice were treated with a 5\% glucose solution (i.p.). Oxa: oxaliplatin, D0: before the injection of oxaliplatin or 5\% glucose, D3: 3 days after the injection of oxaliplatin or 5\% glucose, D5: 5 days following the administration of oxaliplatin or 5\% glucose. Control (5\% glucose): $n=5$, oxaliplatin: $n=5 .{ }^{*} p<0.05,{ }^{* *} p<0.01,{ }^{* * * *} p<0.0001$ vs. Control with two-way ANOVA followed by Sidak's post-test for multiple comparisons.

(a)

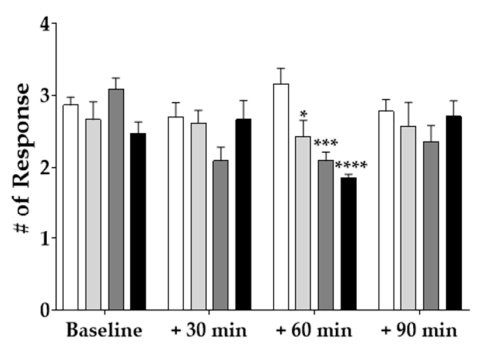

(c)

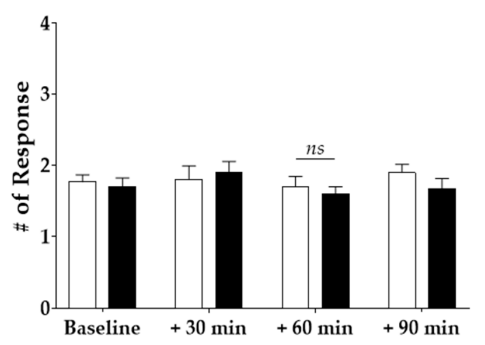

(b) Von Frey Test

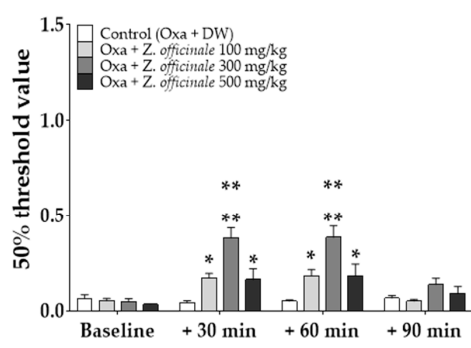

(d)

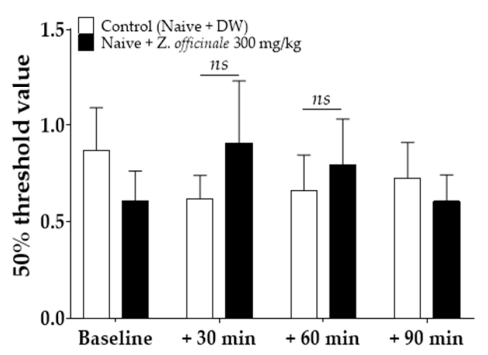

Figure 2. Time-dependent effect of Zingiber officinale on cold and mechanical allodynia induced by oxaliplatin (a,b). Timedependent effect of Z. officinale in naïve mice $(\mathbf{c}, \mathbf{d})$. The effect of the oral administration of Z. officinale on cold (a) and mechanical (b) allodynia induced by a single oxaliplatin $(6 \mathrm{mg} / \mathrm{kg}$, i.p.) injection. Cold and mechanical allodynia were assessed by using the acetone drop and von Frey filament tests, respectively. Effect of Z. officnale administration (p.o.) on cold (c) and mechanical (d) stimuli in naïve mice. For cold and mechanical stimuli, acetone drop and von Frey filament tests were used, respectively. Distilled water (DW) was used as control. Control (Oxa + DW): $n=10$, Oxa + Z. officinale $100 \mathrm{mg} / \mathrm{kg}$ : $n=7$, Oxa + Z. officinale $300 \mathrm{mg} / \mathrm{kg}: n=7$, Oxa + Z. officinale $500 \mathrm{mg} / \mathrm{kg}: n=7(\mathbf{a}, \mathbf{b})$. Control (Naïve + DW): $n=5, \mathrm{Naïve}+Z$. officinale $300 \mathrm{mg} / \mathrm{kg}: n=5$ (c,d). Baseline: before the injection of DW or Z. officinale, ns: non-significant, ${ }^{*} p<0.05,{ }^{* *} p<0.01$, ${ }^{* * *} p<0.001,{ }^{* * * *} p<0.0001$ vs. Control with two-way ANOVA followed by Sidak's post-test for multiple comparisons. 


\subsection{Spinal 5-HT Receptors Are Involved in the Neuropathic Pain-Alleviating Effect of Z. officinale}

To determine whether spinal 5-HT receptors are involved in the effect of $Z$. officinale against oxaliplatin-induced neuropathic pain, methysergide (mixed $5-\mathrm{HT}_{1}$ and $5-\mathrm{HT}_{2}$ antagonists) or MDL-72222 (5-- $\mathrm{HT}_{3}$ antagonist) was intrathecally injected $20 \mathrm{~min}$ before $Z$. officinale treatment, as explained in materials and methods. Our results showed that the analgesic effects of $Z$. officinale on oxaliplatin-induced cold and mechanical allodynia were significantly blocked by methysergide pre-treatment, as the effect of $Z$. officinale was nullified in the Oxa + methysergide $+Z$. officinale group (Figure 3a,b). However, MDL72222 failed to completely block the analgesic action of $Z$. officinale, as only cold but not mechanical allodynia was nullified after Z. officinale treatment (Figure 3c,d). These results showed that spinal $5-\mathrm{HT}_{1}$ and $5-\mathrm{HT}_{2}$ receptors are involved in the anti-allodynic effect of Z. officinale against both cold and mechanical allodynia, whereas $5-\mathrm{HT}_{3}$ receptors are only involved in its anti-allodynic effect against cold allodynia. As 5- $\mathrm{HT}_{3}$ receptors are only partially involved in the pain-alleviating effect of $Z$. officinale, the next study was focused on spinal $5-\mathrm{HT}_{1}$ and $5-\mathrm{HT}_{2}$ receptors.

(a)

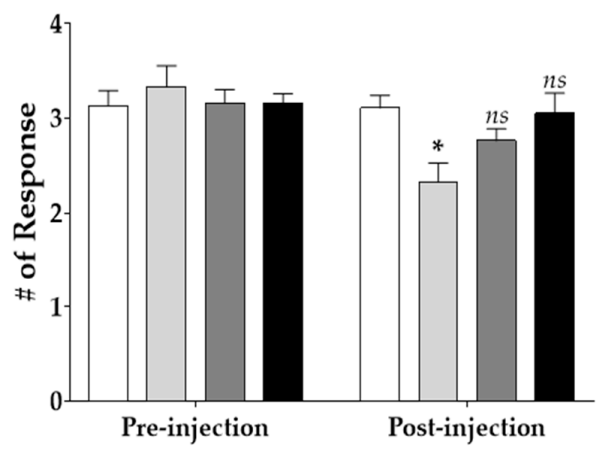

(c)

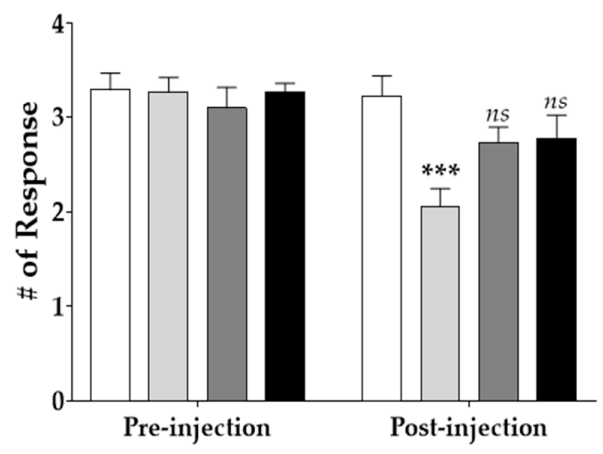

(b) Von Frey Test

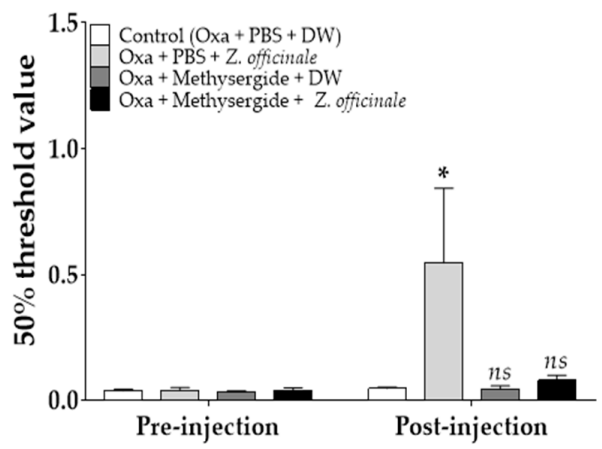

(d)

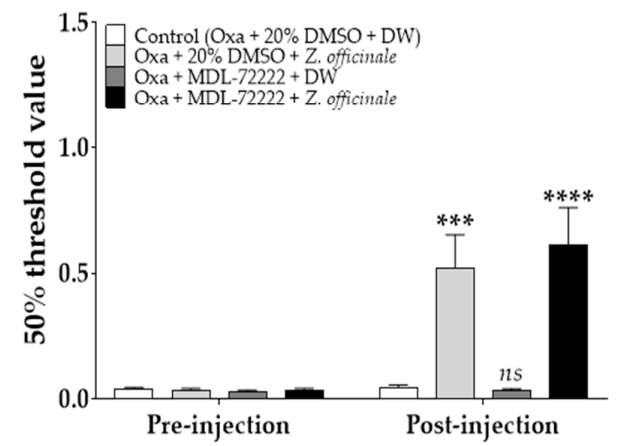

Figure 3. Effect of intrathecal administration of serotonin receptor antagonists on the analgesic effect of Z. officinale against oxaliplatin-induced neuropathic pain. The effect of methysergide $(\mathbf{a}, \mathbf{b})$ and MDL-72222 (c,d) on Z. officinale-induced inhibition of cold $(\mathbf{a}, \mathbf{c})$ and mechanical $(\mathbf{b}, \mathbf{d})$ allodynia. When significant allodynic signs were observed in oxaliplatintreated mice, methysergide or MDL-72222 was injected intrathecally in mice. PBS or 20\% DMSO was used as a control for methysergide and MDL-72222, respectively. Z. officinale or DW was administered orally 20 min after the administration of methysergide, MDL-72222, PBS, or 20\% DMSO. Pre-injection: before the injection of PBS, methysergide, 20\% DMSO, MDL-7222, and Z. officinale. Post-injection: After the injection of PBS, methysergide, 20\% DMSO, MDL-7222, and Z. officinale. Cold and mechanical allodynia were assessed by using the acetone drop and von Frey filament tests, respectively. Control $($ Oxa + PBS + DW): $n=6$, Oxa + PBS + Z. officinale $n=6$, Oxa + Methysergide + DW: $n=5$, Oxa + Methysergide + Z. officinale: $n=6(\mathrm{a}, \mathrm{b})$. Control (Oxa + 20\% DMSO + DW): $n=6$, Oxa + 20\% DMSO + Z. officinale: $n=6$, Oxa + MDL-72222 + DW: $n=6$, Oxa + MDL-72222 + Z. officinale: $n=6$ (c, d). ns: non-significant, ${ }^{*} p<0.05,{ }^{* * *} p<0.001,{ }^{* * * *} p<0.0001$ vs. Control (Oxa + PBS + DW or Oxa + 20\% DMSO + DW) with two-way ANOVA followed by Tukey's post-test for multiple comparisons. 


\subsection{Spinal 5-HT $T_{1 A}$ but Not 5-HT $T_{2 A}$ is Involved in the Anti-Allodynic Effect of Z. officinale}

As spinal $5-\mathrm{HT}_{1}$ and $5-\mathrm{HT}_{2}$ receptors were shown to be involved in the analgesic effect of $Z$. officinale against both cold and mechanical allodynia, the next experiments were conducted by using $5-\mathrm{HT}_{1 \mathrm{~A}}$ (NAN-190) or $5-\mathrm{HT}_{2 \mathrm{~A}}$ (ketanserin) antagonists. As reported in the literature, among various $5-\mathrm{HT}_{1}$ and $5-\mathrm{HT}_{2}$ receptors subtypes, both 5$\mathrm{HT}_{1 \mathrm{~A}}$ and 5- $\mathrm{HT}_{2 \mathrm{~A}}$ are known to be deeply involved in pain modulation [24]. NAN-190 or ketanserin was injected $20 \mathrm{~min}$ prior to Z. officinale administration. Pre-treatment with NAN-190 strongly blocked the anti-allodynic effect of Z. officinale on both cold and mechanical allodynia, whereas ketanserin failed to block this effect (Figure 4a,b). This result showed that spinal $5-\mathrm{HT}_{1 \mathrm{~A}}$ but not $5-\mathrm{HT}_{2 \mathrm{~A}}$ receptors are involved in the analgesic effect of Z. officinale.

(a)

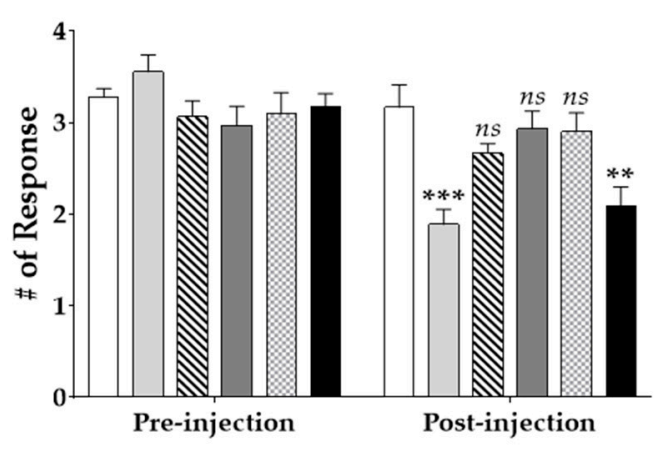

\section{(b) Von Frey Test}

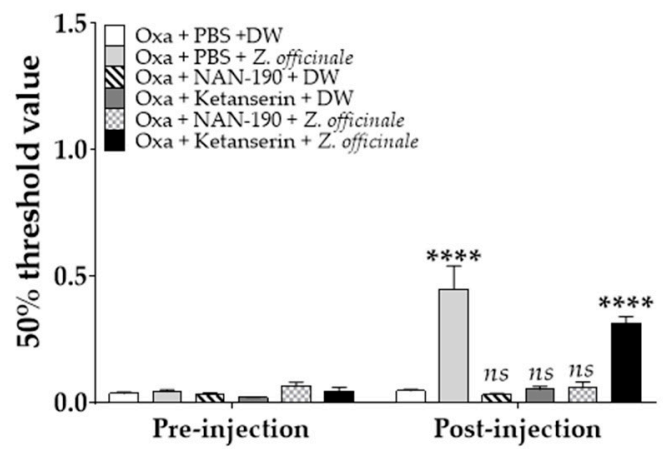

(c)

$5-\mathrm{HT}_{1 \mathrm{~A}}$ Receptors

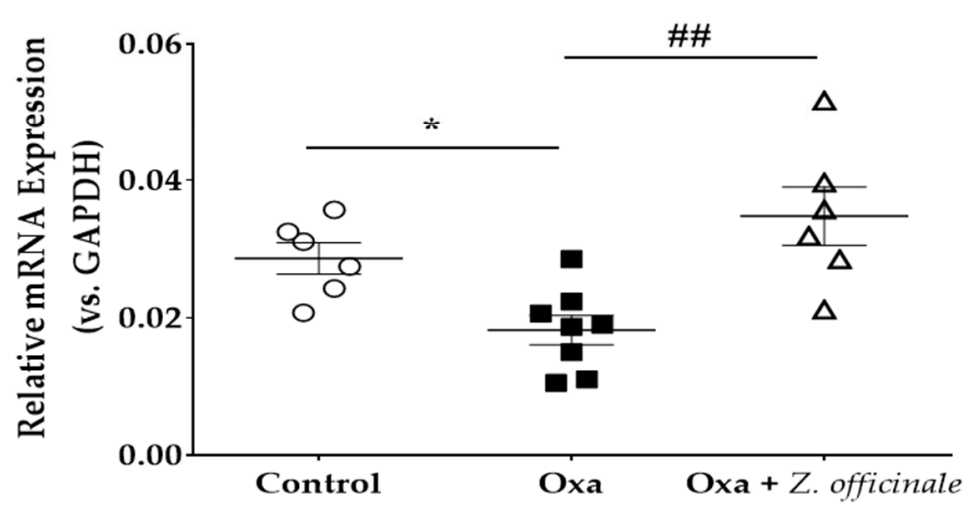

Figure 4. Effect of intrathecal injection of NAN-190 or ketanserin on Z. officinale-dependent inhibition of oxaliplatin-induced neuropathic pain in mice $(\mathbf{a}, \mathbf{b})$. Spinal mRNA expression level of $5-\mathrm{HT}_{1 \mathrm{~A}}$ receptors before and after oxaliplatin and Z. officinale treatment (c). Cold (a) and mechanical (b) allodynia were assessed by using the acetone drop and von Frey filament tests, respectively. On day 3 following oxaliplatin injection, NAN-190 or ketanserin was injected intrathecally in mice. PBS was used as a control for both NAN-190 and ketanserin. The relative mRNA expression of 5-HT $1 \mathrm{~A}$ was measured before and after oxaliplatin injection and Z. officinale treatment (c). Control (Oxa + PBS + DW): $n=6$, Oxa + PBS + Z. officinale: $n=6$, Oxa + NAN-190 + DW: $n=5$, Oxa + Ketanserin + DW: $n=5$, Oxa + NAN-190 + Z. officinale: $n=7$, Oxa + Ketanserin + Z. officinale: $n=7$. ns: non-significant, ${ }^{* *} p<0.01,{ }^{* * *} p<0.001,{ }^{* * * *} p<0.0001$ vs. Control (Oxa + PBS + DW) with two-way ANOVA followed by Tukey's post-test for multiple comparisons (a,b). Control: $n=6$, Oxa: $n=8$, Oxa + Z. officinale: $n=6$. ${ }^{*} p<0.05$ vs. Control, \#\# $p<0.01$ vs. Oxa with one-way ANOVA followed by Tukey's post-test for multiple comparisons (c).

Subsequently, to assess whether the mRNA expression level of spinal $5-\mathrm{HT}_{1 \mathrm{~A}}$ receptor was altered after oxaliplatin and Z. officinale treatment, real-time PCR was conducted to quantify the mRNA expression level of $5-\mathrm{HT}_{1 \mathrm{~A}}$ receptor in the spinal cord. The results showed that the relative mRNA expression level (ratio of $5-\mathrm{HT}_{1 \mathrm{~A}}$ receptor mRNA to 
GAPDH mRNA) of spinal 5- $\mathrm{HT}_{1 \mathrm{~A}}$ receptor was significantly decreased after oxaliplatin treatment (control vs. Oxa, $p<0.05$ ), whereas $Z$. officinale administration significantly up-regulated the decreased mRNA expression level of 5- $\mathrm{HT}_{1 \mathrm{~A}}$ receptor (Oxa vs. Oxa + Z. officinale, $p<0.01$ ), as shown in Figure $4 c$. This indicated that the expression level of spinal $5-\mathrm{HT}_{1 \mathrm{~A}}$ receptor can be modulated by oral administration of $Z$. officinale.

\subsection{Identification of Active Components in Z. officinale by Using HPLC}

To quantify the components of $Z$. officinale contributing to the attenuation of oxaliplatininduced neuropathic pain, HPLC was conducted. By using an established HPLC method, the presence of [6]-gingerol and [6]-shogaol in Z. officinale was confirmed. The retention times of [6]-gingerol and [6]-shogaol from Z. officinale were $5.982 \mathrm{~min}$ and $8.412 \mathrm{~min}$, respectively. The regression equation of [6]-gingerol and [6]-shogaol and the estimated correlation coefficients $\left(r^{2}\right)$ of each phytochemical were determined based on the plots of peak value $(y)$ versus concentrations $(x)$. The regression equation of [6]-gingerol was $y=0.000138 x-0.00140\left(r^{2}=0.999765\right)$. For [6]-shogaol, it was $y=0.000107 x+0.00354$ $\left(r^{2}=0.999600\right)$. The content of [6]-gingerol and [6]-shogaol in a water extract of Z. officinale was $0.012432 \%(310.8 \mu \mathrm{g} / \mathrm{g})$ and $0.007251 \%(181.275 \mu \mathrm{g} / \mathrm{g})$, respectively (Figure 5).

(a)
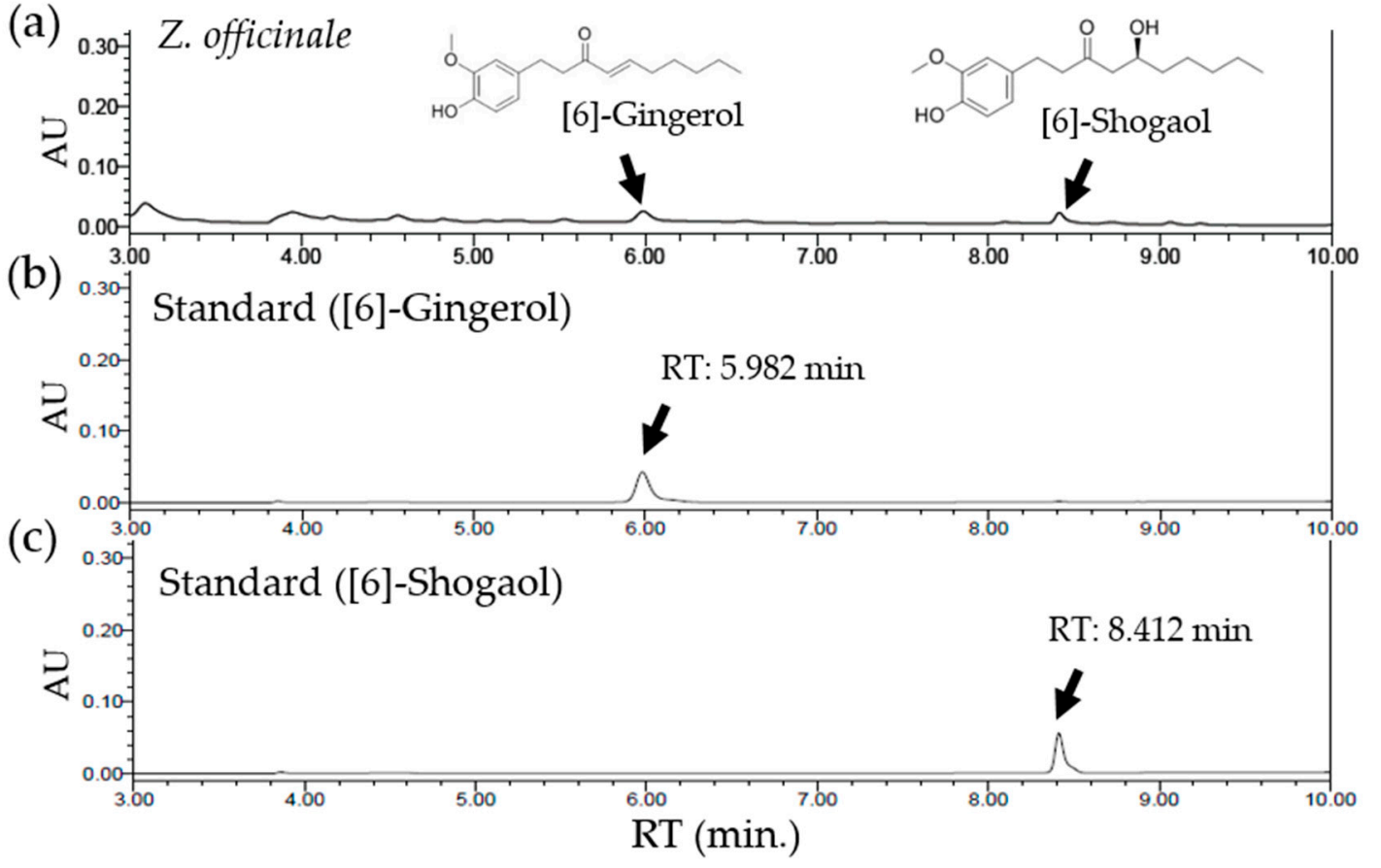

Figure 5. Quantification of chemicals in Z. officinale using HPLC. HPLC chromatograms of a water extract of Z. officinale (a) and of [6]-gingerol (b) and [6]-shogaol (c) as standards. Two peaks in (a) represent [6]-gingerol (5.982 min) and [6]-shogaol (8.412 min), sequentially. The standard ultraviolet detection wavelength was set at $230 \mathrm{~nm}$. The $X$-axis reports the retention time (RT), and the $Y$-axis the absorbance unit (AU).

\section{Discussion}

In this study, we showed for the first time that oral administration of Z. officinale could significantly attenuate allodynia induced by a single oxaliplatin treatment. On cold allodynia, Z. officinale showed dose-dependent $(100,300$, and $500 \mathrm{mg} / \mathrm{kg}$ ) analgesic effects, whereas on mechanical allodynia, the dose of $300 \mathrm{mg} / \mathrm{kg}$ was shown to exhibit the strongest effect. In addition, we demonstrated that spinal $5-\mathrm{HT}_{1 \mathrm{~A}}$ but not $5-\mathrm{HT}_{2 \mathrm{~A}}$ receptors were involved in $Z$. officinale-induced analgesia against cold and mechanical allodynia. $5-\mathrm{HT}_{3}$ receptors were only involved in the cold allodynia-alleviating effect of $Z$. officinale. Finally, we demonstrated that $Z$. officinale treatment could significantly increase 
the mRNA expression of $5-\mathrm{HT}_{1 \mathrm{~A}}$ receptors in the spinal cord, which was down-regulated by oxaliplatin treatment.

Although oxaliplatin is a widely used chemotherapeutic drug, severe peripheral neuropathy induced even after a single injection can decrease the quality of life of the treated patients and may endanger the life of the patients as it can interrupt the treatment schedule. Various mechanisms have been proposed, such as malfunction of voltage-gated sodium [6] and potassium channels [31] in the dorsal root ganglia (DRG) neuronal cells, a change in glial activities [7], and mitochondria dysfunction in peripheral neurons [32]. However, oxaliplatin mechanism of action is not clearly understood, and an alternative effective drug has yet to be developed.

Z. officinale has been widely used from the antiquity as a condiment and herbal medicine. Its therapeutic effects against various diseases have been reported, and some studies also focused on its analgesic effect. Sepehvand et al. showed that intraperitoneal treatment with Z. officinale is able to potentiate morphine-induced analgesia by enhancing the descending pain inhibitory system in rats [11]. Borgonetti et al. reported that oral administration of $Z$. officinale could decrease spinal nerve injury-induced neuropathic pain by inhibiting neuro-inflammation in mice [20]. In accordance with these studies, our results demonstrated that oral administration of $Z$. officinale could significantly attenuate oxaliplatin-induced cold and mechanical allodynia in mice. The main biologically active components of Z. officinale include [6]-gingerol and [6]-shogaol, which are both known to possess analgesic effects in various animal models of pain [33-35]. Furthermore, by using a parallel artificial membrane permeability assay for the blood brain barrier (BBB), both [6]gingerol and [6]-shogaol were shown to be able to passively cross the BBB [36], suggesting that Z. officinale may directly act on the central nervous system (CNS). Moreover, the two compounds were shown to be extremely rapidly absorbed and eliminated following a single administration, as $2 \mathrm{~h}$ after their administration, their plasma levels were significantly decreased [37]. This may explain how a single Z. officinale administration could acutely decrease oxaliplatin-induced neuropathic pain and increase the mRNA expression of the 5-HT receptor in the spinal cord.

In our study, intrathecal pre-treatment with non-selective spinal $5-\mathrm{HT}_{1}$ and $5-\mathrm{HT}_{2}$ receptors antagonist (methysergide) significantly blocked the anti-allodynic effect of $Z$. officinale against both cold and mechanical allodynia, whereas the 5- $\mathrm{HT}_{3}$ receptor antagonist (MDL-72222) only blocked Z. officinale effect against cold allodynia. It has been reported that $5-\mathrm{HT}_{3}$ receptors are mostly present in unmyelinated $\mathrm{C}$-fibers of the spinal dorsal horn [38]. However, according to data obtained from others [6] and our lab [10], oxaliplatininduced neuropathic pain is shown to be mostly mediated by myelinated A-fibers rather than by unmyelinated C-fibers [6,10]. Furthermore, in several studies, cold allodynia is reported to be mediated mostly by unmyelinated fibers [39]. This may explain why blocking $5-\mathrm{HT}_{3}$ receptors only partially attenuated the analgesic effect of $Z$. officinale. Thus, in our following experiments, we focused on spinal 5- $\mathrm{HT}_{1}$ and $5-\mathrm{HT}_{2}$ receptors, as they were shown to be involved in the alleviating effect of $Z$. officinale against both cold and mechanical allodynia.

Our results demonstrated that spinal $5-\mathrm{HT}_{1 \mathrm{~A}}$ but not $5-\mathrm{HT}_{2 \mathrm{~A}}$ receptors are involved in the analgesic effect of $Z$. officinale, as only the 5- $\mathrm{HT}_{1 \mathrm{~A}}$ receptor antagonist (NAN-190) completely blocked the analgesic action of $Z$. officinale against both cold and mechanical allodynia induced by oxaliplatin. In addition, the quantification of $5-\mathrm{HT}_{1 \mathrm{~A}}$ receptors by real-time PCR demonstrated that $Z$. officinale significantly increased the lowered mRNA expression level of spinal $5-\mathrm{HT}_{1 \mathrm{~A}}$ receptor. The $5-\mathrm{HT}_{1 \mathrm{~A}}$ receptor is a $\mathrm{G}$ protein-coupled receptor widely present in the CNS. In the spinal cord, $5-\mathrm{HT}_{1 \mathrm{~A}}$ receptors are known to be expressed by spinothalamic interneurons in the superficial as well as deeper laminae and by gamma-aminobutyric acid(GABA)ergic interneurons in the spinal dorsal horn $[40,41]$. Various studies have reported that a spinal injection of the $5-\mathrm{HT}_{1}$ A receptor agonist 8hydroxy-2-(di-n-propylamino)tetralin resulted in attenuation of pain $[42,43]$. Morphological studies have reported that spinal 5- $\mathrm{HT}_{2 \mathrm{~A}}$ receptors are also present in the laminae I-IV 
of the spinal dorsal horn; however, contrary to spinal 5- $\mathrm{HT}_{1 \mathrm{~A}}$ receptors, $5-\mathrm{HT}_{2 \mathrm{~A}}$ receptors are reported to be involved in the development of inflammatory and neuropathic pain [44]. In a vincristine-induced neuropathic pain animal model, it was shown that $5-\mathrm{HT}_{2 \mathrm{~A}}{ }^{-/-}$ mutant mice did not develop vincristine-induced allodynia or hypersensitivity, whereas their $5-\mathrm{HT}_{2 \mathrm{~A}}^{+/+}$littermates showed significant signs of pain. Furthermore, epidural injection a $5-\mathrm{HT}_{2 \mathrm{~A}}$ receptor antagonist attenuated thermal and mechanical allodynia, showing that spinal 5- $\mathrm{HT}_{2 \mathrm{~A}}$ receptors are more involved in facilitating than in inhibiting the effect of pain [45]. Altogether, these results indicate that spinal $5-\mathrm{HT}_{1 \mathrm{~A}}$ receptors may play an important role in the anti-allodynic effect of $Z$. officinale. In line with this, Nievergelt et al. reported that various sub-components of ginger can interact with the human $5-\mathrm{HT}_{1 \mathrm{~A}}$ receptor with significant to moderate binding affinities [46].

\section{Materials and Methods}

\subsection{Animals}

Adult C57BL/ 6 mice (6 weeks old) were obtained from Daehan biolink (Chungbuk, Korea) and housed in a specific pathogen-free animal center. Animals were randomly distributed in cages. They were kept in a room with a temperature of $23 \pm 2{ }^{\circ} \mathrm{C}$, humidity of $65 \pm 5 \%$, fixed $12 \mathrm{~h}$ light/dark cycle, and with food and water ad libitum. All experimental protocols were approved by the Kyung Hee University Animal Care and Use Committee (KHUASP(SE)-20-448) on 15 November 2020 and were conducted in accordance with the guidelines of the International Association for the Study of Pain [47].

\subsection{Oxaliplatin Administration}

Oxaliplatin (Sigma Aldrich, St. Louis, MO, USA) was dissolved in a 5\% glucose solution at a concentration of $2 \mathrm{mg} / \mathrm{mL}$, as in our previous study [10]. Oxaliplatin was administered to mice intraperitoneally in an amount of $6 \mathrm{mg} / \mathrm{kg}$. For control, the same amount of a 5\% glucose solution was used. To assess whether oxaliplatin administration induced cold and mechanical allodynia in mice, behavioral tests were conducted before (baseline), 3 (D3), and 5 (D5) days after its injection.

\subsection{Preparation of and Treatment with Z. Officinale}

The dried root of Z. officinale (rhizome of Zingiber officinale roscoe) used in the experiments was procured from Yaksudang Pharmaceutical limited company (Seoul, Korea). The voucher specimen number was deposited as D200909001. Z. officinale was extracted using a reflux apparatus (distilled water (DW), $3 \mathrm{~h}$ at $100{ }^{\circ} \mathrm{C}$ ). The extracted solution was filtered and condensed using a low-pressure evaporator. The Z. officinale extract had a yield of $17.53 \%$ after freeze-drying at $-80^{\circ} \mathrm{C}$. The lyophilized Z. officinale powder was diluted in DW to obtain a stock solution of $80 \mathrm{mg} / \mathrm{mL}$. Z. officinale was orally administered at three different doses $(100,300$, and $500 \mathrm{mg} / \mathrm{kg})$. The same volume $(0.3 \mathrm{~mL})$ of DW was orally administered to control animals.

\subsection{Treatment with Serotonergic Antagonists}

To assess the involvement of spinal serotonergic receptors in the analgesic effect of Z. Officinale against oxaliplatin-induced neuropathic pain, serotonin receptor antagonists were intrathecally injected $20 \mathrm{~min}$ before the oral administration of $Z$. officinale. The 5-HT receptor antagonists used in the experiments were methysergide (mixed 5- $\mathrm{HT}_{1}$ and 2 receptor antagonists, $10 \mu \mathrm{g}$, concentration $2 \mu \mathrm{g} / \mu \mathrm{L})$, NAN-190 (5- $\mathrm{HT}_{1 \mathrm{~A}}$ receptor antagonist, $1 \mu \mathrm{g}$, concentration $0.2 \mu \mathrm{g} / \mu \mathrm{L})$, ketanserin $\left(5-\mathrm{HT}_{2 \mathrm{~A}}\right.$ receptor antagonist, $1 \mu \mathrm{g}$, concentration $0.2 \mu \mathrm{g} / \mu \mathrm{L}$ ), and MDL-72222 (3-tropanyl-3,5-dichlorobenzoate, 5- $\mathrm{HT}_{3}$ receptor antagonist, $15 \mu \mathrm{g}$, concentration $3 \mu \mathrm{g} / \mu \mathrm{l})$. All antagonists used in this study were purchased from Tocris (Cookson, UK). Under isoflurane anesthesia (2-2.5\% in $\left.\mathrm{N}_{2} \mathrm{O} / \mathrm{O}_{2}: 1: 1 v / v\right), 5 \mu \mathrm{L}$ of antagonist solutions was injected at the lumbar 5-6 intervertebral level by using a Hamilton syringe (Hamilton Company, Reno, NV, USA) to deliver the drug directly into 
the subarachnoid space, as in our previous study [26]. For control, $5 \mu \mathrm{L}$ of solvents (PBS or $20 \%$ dimethyl sulfoxide (DMSO)) was injected.

\subsection{Behavioral Assessments}

Behavior tests were conducted to assess the degree of allodynia in mice, as in our previous study [10]. Cold allodynia and mechanical allodynia were measured by using the acetone drop and von Frey filament tests, respectively. For acclimation, the animals were placed on a metal mesh floor and were caged in an inverted clear plastic cage $(12 \times 8 \times$ $6 \mathrm{~cm}^{3}$ ) for $30 \mathrm{~min}$ before all behavioral tests. To assess the behavioral responses against cold stimuli, an acetone drop $(10 \mu \mathrm{L})$ was applied on the mid-plantar hind paw of the mice. The behavioral responses (flicking and licking) against the stimulus were observed and counted for $30 \mathrm{sec}$. Thus, the term "\# of response" mentioned in the figures stands for the average number of responses to an acetone drop of $10 \mu \mathrm{L}$, counted for $30 \mathrm{~s}$.

To measure mechanical allodynia, a series of von Frey filaments (bending force of 0.02, $0.04,0.07,0.16,0.4,0.6,1,1.4,2$ g, Stoelting, Kiel, WI, USA) were applied on the mid-plantar hind paws. The Dixon's up-down method and Chaplan's calculation method were used, and a withdrawal threshold of $15 \mathrm{~g}$ was applied as the cut-off $[48,49]$. The results obtained from both hind paws were averaged.

\subsection{Behavioral Tests Schedules}

Behavioral tests were conducted with different timelines in each experiment. To measure the analgesic effect of $Z$. officinale against oxaliplatin-induced cold and mechanical allodynia, behavioral tests were conducted before (baseline) and 30, 60, and 90 min after Z. officinale oral administration on day 3 following oxaliplatin injection. To determine the role of spinal 5-HT receptors in the analgesic effects of Z. officinale, behavioral tests were conducted before the injection of antagonists (pre-injection) and $60 \mathrm{~min}$ after Z. officinale treatment (post-injection). Z. officinale was administered $20 \mathrm{~min}$ after the intrathecal injection of the antagonists.

\subsection{High-Performance Liquid Chromatography (HPLC) Analysis of the Z. officinale Extract}

A quantitative analysis of Z. officinale was carried out by the HPLC alliance system, with a 2998 photodiode array detector (Waters, Milford, MA, USA). Separation was done at $30{ }^{\circ} \mathrm{C}$ on a $\mathrm{C}_{18}$ column (Waters, Milford, MA, USA; $5 \mu \mathrm{m}, 150 \times 4.6 \mathrm{~mm}^{2}$ ). The sample injection volume was $10 \mu \mathrm{L}$. The compounds [6]-gingerol $(2 \mathrm{mg} / \mathrm{mL})$ and [6]-shogaol $(2 \mathrm{mg} / \mathrm{mL}$ ) were dissolved in acetonenitrile and used as standards to qualify and quantify components of Z. officinale. At a flow rate of $1.1 \mathrm{~mL} / \mathrm{min}$, mobile phase A (water) and mobile phase $B$ (acetonenitrile) were operated using a gradient program (0-1.5 min, hold $35 \% \mathrm{~B} ; 1.5-1.8 \mathrm{~min}$, from 35 to $60 \% \mathrm{~B} ; 1.8-5 \mathrm{~min}$, hold $60 \% \mathrm{~B} ; 5-6.5 \mathrm{~min}$, from 60 to $100 \%$ B; 6.5-9 min, hold 100\% B; 9-9.1 min, 100-35\% B; 9.1-12 min, hold 35\% B). The standard ultraviolet detector wavelength was set at $230 \mathrm{~nm}$ [50].

\subsection{RNA Extraction and Real-Time PCR}

When Z. officinale induced significant attenuation of cold and mechanical allodynia, animals were perfused with PBS, and the lumbar segments of the spinal cord were collected. Collected spinal cords were homogenized with Easy Blue (Intron Company, Seongnam, Korea) solution. RNA was extracted from the spinal cord, following the manufacturer's protocol. The extracted RNA was qualified and quantified by NanoDrop (ThermoFisher, Waltham, MA, USA) and converted to complementary DNA (cDNA) using a cDNA synthesis kit (Bioneer Corporation, Daejeon, Korea). The mRNA level of 5- $\mathrm{HT}_{1 \mathrm{~A}}$ (HTR1A) was determined with SYBR Green qPCR Mastermix (Bioline Reagents Ltd., London, United Kingdom) in a CFX Connect Real-Time PCR system (Bio-Rad, Laboratories Inc., Hercules, CA, USA). Data are expressed as the ratio of targeted mRNA to glyceraldehyde 3-phosphate dehydrogenase (GAPDH) mRNA (relative mRNA expression). The following table lists the PCR primers used in the experiments (Table 1). 
Table 1. PCR primer sequences for PCR analysis.

\begin{tabular}{cc}
\hline Type & Sequence \\
\hline GAPDH (Forward) & $5^{\prime}$-GGAGGTAGCTCCTGATTCGC-3' \\
\hline GAPDH (Reverse) & $5^{\prime}$-CACATTGGGGGTAGGAACAC-3' $^{\prime}$ \\
\hline HTR1A (Forward) & $5^{\prime}$-TACTCCACTTTCGGCGCTTT-3' \\
\hline HTR1A (Reverse) & $5^{\prime}$-GGAGGTAGCTCCTGATTCGC-3' \\
\hline
\end{tabular}

\subsection{Statistical Analysis}

All data were presented as mean \pm standard error of the mean (SEM). Statistical analysis and graphic works were performed by using Prism 7.0 (GraphPad software, La Jolla, CA, USA). Two-way ANOVA (analysis of variance) followed by Sidak's or Tukey's post-test for multiple comparisons and student $\mathrm{t}$-test were used for statistical analyses. In all cases, $p<0.05$ was considered to indicate significant differences.

\section{Conclusions}

In conclusion, our study demonstrated that the oral administration of different doses of $Z$. officinale could significantly attenuate oxaliplatin-induced cold and mechanical allodynia and that both spinal 5- $\mathrm{HT}_{1 \mathrm{~A}}$ and $5-\mathrm{HT}_{3}$ receptors are involved in $\mathrm{Z}$. officinale analgesic effect against cold allodynia, whereas only spinal $5-\mathrm{HT}_{1 \mathrm{~A}}$, but not $5-\mathrm{HT}_{3}$ receptors, are involved against mechanical allodynia. In addition, Z. officinale administration could increase the mRNA expression level of spinal $5-\mathrm{HT}_{1 \mathrm{~A}}$ receptors that was reduced after oxaliplatin treatment. Future studies are needed to clearly elucidate the involvement of the 5-HT system in the analgesic action of Z. officinale and its sub-components against oxaliplatin-induced neuropathic pain.

\section{Patent}

The content of this article are related to a patent application in Korea (10-2020-0189163).

Author Contributions: Conceptualization, W.K.; methodology, J.H.L., D.M., D.L., and W.K.; formal analysis, J.H.L. and W.K.; investigation, J.H.L. and W.K.; resources, D.L.; data curation, J.H.L. and D.M.; writing-original draft preparation, J.H.L. and W.K.; writing-review and editing, J.H.L. and W.K.; project administration, W.K.; funding acquisition, W.K. All authors have read and agreed to the published version of the manuscript.

Funding: This work was supported by the National Research Foundation of Korea (NRF) grant funded by the Korea government (MSIT) (no. 2020R1A5A201941311).

Institutional Review Board Statement: All experimental procedures were approved by the Kyung Hee University Animal Care and Use Committee (KHUASP(SE)-20-448) on 15 November 2020.

Informed Consent Statement: Not applicable.

Data Availability Statement: The data presented in this study are openly available.

Conflicts of Interest: The authors declare no conflict of interest.

Sample Availability: Sample of water extract of Z. officinale is available from the authors (voucher specimen number was deposited as D200909001).

\section{References}

1. Graham, J.; Muhsin, M.; Kirkpatrick, P. Oxaliplatin; Nature Publishing Group: Berlin, Germany, 2004.

2. Di Francesco, A.; Ruggiero, A.; Riccardi, R. Cellular and molecular aspects of drugs of the future: Oxaliplatin. Cell. Mol. Life Sci. CMLS 2002, 59, 1914-1927. [CrossRef] [PubMed]

3. Ta, L.E.; Low, P.A.; Windebank, A.J. Mice with cisplatin and oxaliplatin-induced painful neuropathy develop distinct early responses to thermal stimuli. Mol. Pain 2009, 5, 9. [CrossRef] [PubMed]

4. Lehky, T.; Leonard, G.; Wilson, R.; Grem, J.; Floeter, M. Oxaliplatin-induced neurotoxicity: Acute hyperexcitability and chronic neuropathy. Muscle Nerve 2004, 29, 387-392. [CrossRef] [PubMed] 
5. Pachman, D.R.; Qin, R.; Seisler, D.K.; Smith, E.M.L.; Beutler, A.S.; Ta, L.E.; Lafky, J.M.; Wagner-Johnston, N.; Ruddy, K.J.; Dakhil, S.R. Clinical course of patients with oxaliplatin-associated neuropathy: N08cb (alliance). Am. Soc. Clin. Oncol. 2014, $32,3595$. [CrossRef]

6. Kim, W. Effect of oxaliplatin on voltage-gated sodium channels in peripheral neuropathic pain. Processes 2020, 8, 680. [CrossRef]

7. Lee, J.H.; Kim, W. The role of satellite glial cells, astrocytes, and microglia in oxaliplatin-induced neuropathic pain. Biomedicines 2020, 8, 324. [CrossRef]

8. Kim, W.; Kim, M.J.; Go, D.; Min, B.-I.; Na, H.S.; Kim, S.K. Combined effects of bee venom acupuncture and morphine on oxaliplatin-induced neuropathic pain in mice. Toxins 2016, 8, 33. [CrossRef] [PubMed]

9. Kim, W.; Chung, Y.; Choi, S.; Min, B.-I.; Kim, S.K. Duloxetine protects against oxaliplatin-induced neuropathic pain and spinal neuron hyperexcitability in rodents. Int. J. Mol. Sci. 2017, 18, 2626. [CrossRef] [PubMed]

10. Lee, J.H.; Gang, J.; Yang, E.; Kim, W.; Jin, Y.-H. Bee venom acupuncture attenuates oxaliplatin-induced neuropathic pain by modulating action potential threshold in a-fiber dorsal root ganglia neurons. Toxins 2020, 12, 737. [CrossRef]

11. Sepahvand, R.; Esmaeili-Mahani, S.; Arzi, A.; Rasoulian, B.; Abbasnejad, M. Ginger (Zingiber officinale roscoe) elicits antinociceptive properties and potentiates morphine-induced analgesia in the rat radiant heat tail-flick test. J. Med. Food 2010, 13, $1397-1401$. [CrossRef] [PubMed]

12. White, B. Ginger: An overview. Am. Fam. Phys. 2007, 75, 1689-1691.

13. Langner, E.; Greifenberg, S.; Gruenwald, J. Ginger: History and use. Adv. Ther. 1998, 15, 25-44. [PubMed]

14. Prasad, S.; Tyagi, A.K. Ginger and its constituents: Role in prevention and treatment of gastrointestinal cancer. Gastroenterol. Res. Pract. 2015, 2015, 142979. [CrossRef] [PubMed]

15. Habib, S.H.M.; Makpol, S.; Hamid, N.A.A.; Das, S.; Ngah, W.Z.W.; Yusof, Y.A.M. Ginger extract (Zingiber officinale) has anti-cancer and anti-inflammatory effects on ethionine-induced hepatoma rats. Clinics 2008, 63, 807-813. [CrossRef]

16. Ojewole, J.A. Analgesic, antiinflammatory and hypoglycaemic effects of ethanol extract of Zingiber officinale (roscoe) rhizomes (zingiberaceae) in mice and rats. Phytother. Res. 2006, 20, 764-772. [CrossRef]

17. Haniadka, R.; Rajeev, A.G.; Palatty, P.L.; Arora, R.; Baliga, M.S. Zingiber officinale (ginger) as an anti-emetic in cancer chemotherapy: A review. J. Altern. Complement. Med. 2012, 18, 440-444. [CrossRef]

18. Black, C.D.; Herring, M.P.; Hurley, D.J.; O'Connor, P.J. Ginger (Zingiber officinale) reduces muscle pain caused by eccentric exercise. J. Pain 2010, 11, 894-903. [CrossRef]

19. Fajrin, F.A.; Nurrochmad, A.; Nugroho, A.E.; Susilowati, R. The improvement of pain behavior and sciatic nerves morphology in mice model of painful diabetic neuropathy upon administration of ginger (Zingiber officinale roscoe.) extract and its pungent compound, 6-shogaol. J. Nat. Sci. Biol. Med. 2019, 10, 149.

20. Borgonetti, V.; Governa, P.; Biagi, M.; Pellati, F.; Galeotti, N. Zingiber officinale roscoe rhizome extract alleviates neuropathic pain by inhibiting neuroinflammation in mice. Phytomedicine 2020, 78, 153307. [CrossRef]

21. Sommer, C. Serotonin in pain and pain control. In Handbook of Behavioral Neuroscience; Elsevier: Amsterdam, The Netherlands, 2010; Volume 21, pp. 457-471.

22. Millan, M.J. Descending control of pain. Prog. Neurobiol. 2002, 66, 355-474. [CrossRef]

23. Barnes, N.M.; Sharp, T. A review of central 5-ht receptors and their function. Neuropharmacology 1999, 38, 1083-1152. [CrossRef]

24. Bardin, L. The complex role of serotonin and 5-ht receptors in chronic pain. Behav. Pharmacol. 2011, 22, 390-404. [CrossRef] [PubMed]

25. Bardin, L.; Lavarenne, J.; Eschalier, A. Serotonin receptor subtypes involved in the spinal antinociceptive effect of 5-ht in rats. Pain 2000, 86, 11-18. [CrossRef]

26. Li, D.; Lee, J.H.; Choi, C.W.; Kim, J.; Kim, S.K.; Kim, W. The analgesic effect of venlafaxine and its mechanism on oxaliplatininduced neuropathic pain in mice. Int. J. Mol. Sci. 2019, 20, 1652. [CrossRef] [PubMed]

27. Lee, J.-H.; Li, D.X.; Yoon, H.; Go, D.; Quan, F.S.; Min, B.-I.; Kim, S.K. Serotonergic mechanism of the relieving effect of bee venom acupuncture on oxaliplatin-induced neuropathic cold allodynia in rats. BMC Complement. Altern. Med. 2014, 14, 471. [CrossRef]

28. Hershman, D.L.; Lacchetti, C.; Dworkin, R.H.; Lavoie Smith, E.M.; Bleeker, J.; Cavaletti, G.; Chauhan, C.; Gavin, P.; Lavino, A.; Lustberg, M.B. Prevention and management of chemotherapy-induced peripheral neuropathy in survivors of adult cancers: American society of clinical oncology clinical practice guideline. J. Clin. Oncol. 2014, 32, 1941-1967. [CrossRef]

29. Stahl, S.M.; Grady, M.M.; Moret, C.; Briley, M. Snris: The pharmacology, clinical efficacy, and tolerability in comparison with other classes of antidepressants. CNS Spectr. 2005, 10, 732-747. [CrossRef]

30. Zimmerman, C.; Atherton, P.J.; Pachman, D.; Seisler, D.; Wagner-Johnston, N.; Dakhil, S.; Lafky, J.M.; Qin, R.; Grothey, A.; Loprinzi, C.L. Mc11c4: A pilot randomized, placebo-controlled, double-blind study of venlafaxine to prevent oxaliplatin-induced neuropathy. Support. Care Cancer 2016, 24, 1071-1078. [CrossRef]

31. Kagiava, A.; Tsingotjidou, A.; Emmanouilides, C.; Theophilidis, G. The effects of oxaliplatin, an anticancer drug, on potassium channels of the peripheral myelinated nerve fibres of the adult rat. Neurotoxicology 2008, 29, 1100-1106. [CrossRef]

32. Zheng, H.; Xiao, W.H.; Bennett, G.J. Functional deficits in peripheral nerve mitochondria in rats with paclitaxel-and oxaliplatinevoked painful peripheral neuropathy. Exp. Neurol. 2011, 232, 154-161. [CrossRef]

33. Hitomi, S.; Ono, K.; Terawaki, K.; Matsumoto, C.; Mizuno, K.; Yamaguchi, K.; Imai, R.; Omiya, Y.; Hattori, T.; Kase, Y. [6]-gingerol and [6]-shogaol, active ingredients of the traditional japanese medicine hangeshashinto, relief oral ulcerative mucositis-induced pain via action on $\mathrm{Na}^{+}$channels. Pharmacol. Res. 2017, 117, 288-302. [CrossRef] [PubMed] 
34. Gauthier, M.L.; Beaudry, F.; Vachon, P. Intrathecal [6]-gingerol administration alleviates peripherally induced neuropathic pain in male sprague-dawley rats. Phytother. Res. 2013, 27, 1251-1254. [CrossRef] [PubMed]

35. Fajrin, F.A.; Nugroho, A.E.; Nurrochmad, A.; Susilowati, R. Ginger extract and its compound, 6-shogaol, attenuates painful diabetic neuropathy in mice via reducing trpv1 and nmdar2b expressions in the spinal cord. J. Ethnopharmacol. 2020, $249,112396$. [CrossRef] [PubMed]

36. Simon, A.; Darcsi, A.; Kéry, Á.; Riethmüller, E. Blood-brain barrier permeability study of ginger constituents. J. Pharm. Biomed. Anal. 2020, 177, 112820. [CrossRef]

37. Jiang, S.Z.; Wang, N.S.; Mi, S.Q. Plasma pharmacokinetics and tissue distribution of [6]-gingerol in rats. Biopharm. Drug Dispos. 2008, 29, 529-537. [CrossRef]

38. Kia, H.K.; Miquel, M.-C.; McKernan, R.M.; Laporte, A.-M.; Lombard, M.-C.; Bourgoin, S.; Hamon, M.; Vergé, D. Localization of 5-ht3 receptors in the rat spinal cord: Immunohistochemistry and in situ hybridization. Neuroreport 1995, 6, 257-261. [CrossRef]

39. Serra, J.; Solà, R.; Quiles, C.; Casanova-Molla, J.; Pascual, V.; Bostock, H.; Valls-Solé, J. C-nociceptors sensitized to cold in a patient with small-fiber neuropathy and cold allodynia. Pain 2009, 147, 46-53. [CrossRef]

40. Wang, Y.-Y.; Wei, Y.-Y.; Huang, J.; Wang, W.; Tamamaki, N.; Li, Y.-Q.; Wu, S.-X. Expression patterns of 5-ht receptor subtypes 1a and 2a on gabaergic neurons within the spinal dorsal horn of gad67-gfp knock-in mice. J. Chem. Neuroanat. 2009, 38, 75-81. [CrossRef]

41. Marlier, L.; Teilhac, J.-R.; Cerruti, C.; Privat, A. Autoradiographic mapping of 5-ht1, 5-ht1a, 5-ht1b and 5-ht2 receptors in the rat spinal cord. Brain Res. 1991, 550, 15-23. [CrossRef]

42. Nadeson, R.; Goodchild, C. Antinociceptive role of 5-ht1a receptors in rat spinal cord. Br. J. Anaesth. 2002, 88, 679-684. [CrossRef]

43. Bardin, L.; Tarayre, J.-P.; Koek, W.; Colpaert, F.C. In the formalin model of tonic nociceptive pain, 8-oh-dpat produces 5-ht1a receptor-mediated, behaviorally specific analgesia. Eur. J. Pharmacol. 2001, 421, 109-114. [CrossRef]

44. Van Steenwinckel, J.; Noghero, A.; Thibault, K.; Brisorgueil, M.-J.; Fischer, J.; Conrath, M. The 5-ht2a receptor is mainly expressed in nociceptive sensory neurons in rat lumbar dorsal root ganglia. Neuroscience 2009, 161, 838-846. [CrossRef] [PubMed]

45. Thibault, K.; Van Steenwinckel, J.; Brisorgueil, M.-J.; Fischer, J.; Hamon, M.; Calvino, B.; Conrath, M. Serotonin 5-ht2a receptor involvement and fos expression at the spinal level in vincristine-induced neuropathy in the rat. Pain 2008, 140, 305-322. [CrossRef] [PubMed]

46. Nievergelt, A.; Huonker, P.; Schoop, R.; Altmann, K.-H.; Gertsch, J. Identification of serotonin 5-ht1a receptor partial agonists in ginger. Bioorg. Med. Chem. 2010, 18, 3345-3351. [CrossRef]

47. Zimmermann, M. Ethical guidelines for investigations of experimental pain in conscious animals. Pain 1983, 16, 109-110. [CrossRef]

48. Dixon, W.J. Efficient analysis of experimental observations. Annu. Rev. Pharmacol. Toxicol. 1980, 20, 441-462. [CrossRef]

49. Chaplan, S.R.; Bach, F.W.; Pogrel, J.W.; Chung, J.M.; Yaksh, T.L. Quantitative assessment of tactile allodynia in the rat paw. J. Neurosci. Methods 1994, 53, 55-63. [CrossRef]

50. You, H.; Ireland, B.; Moeszinger, M.; Zhang, H.; Snow, L.; Krepich, S.; Takagawa, V. Determination of bioactive nonvolatile ginger constituents in dietary supplements by a rapid and economic hplc method: Analytical method development and single-laboratory validation. Talanta 2019, 194, 795-802. [CrossRef] 